\title{
Relationship among Subjective Satisfaction with Verbal Communication, Dental Status, and Health-Related Quality of Life in Japanese Community-Residing Elderly Individuals
}

\author{
Shuichi Hara1, Hiroko Miura' ${ }^{2}$ Kiyoko Yamasaki ${ }^{3}$, Naoko Morisaki ${ }^{4}$, Ken Osaka ${ }^{5}$ \\ ${ }^{1}$ School of Health Science, Kyushu University of Health and Welfare, Nobeoka, Japan \\ ${ }^{2}$ Department of International Health and Collaboration, National Institute of Public Health, Wako, Japan \\ ${ }^{3}$ School of Social Welfare, Kyushu University of Health and Welfare, Nobeoka, Japan \\ ${ }^{4}$ School of Nursing, University of Kindai Himeji, Himeji, Japan \\ ${ }^{5}$ Graduate School of Dentistry, Tohoku University, Sendai, Japan \\ Email: harashu@phoenix.ac.jp
}

Received 16 November 2014; revised 3 December 2014; accepted 18 December 2014

Copyright (C) 2015 by authors and Scientific Research Publishing Inc.

This work is licensed under the Creative Commons Attribution International License (CC BY). http://creativecommons.org/licenses/by/4.0/

(c) (i) Open Access

\section{Abstract}

Aim: We aimed to explore factors related to improving health-related quality of life (HRQOL) among Japanese community-residing elderly individuals. Using a questionnaire, we investigated subjective satisfaction with verbal communication, dental status, and HRQOL in community-residing elderly people. Methods: Subjects were 454 independent elderly individuals, with a mean age of 76.1 \pm 6.8 years, living in Japan. The Japanese version of the SF-8 Health Survey was used to evaluate HRQOL. Subjective satisfaction with verbal communication was investigated using a fivepoint scale. Multiple regression analysis was conducted to identify determinants affecting HRQOL. Covariance structure analysis was conducted to investigate any mutual association between age, presence of natural teeth, satisfaction with verbal communication, and HRQOL. Results: The HRQOL scores of subjects who answered that they were "very satisfied" or "satisfied" with verbal communication were significantly higher than those of subjects in the groups of "neither satisfied nor unsatisfied", the "unsatisfied", and the "very unsatisfied" in physical component summary (PCS) scores or mental component summary (MCS) scores of SF-8 $(P<0.001)$. In multiple regression analysis, age, gender, and satisfaction with verbal communication were independent predictors of PCS scores. Furthermore, age and subjective satisfaction with verbal communication were also independent predictors of MCS scores. There was a significant positive correlation between sub- 
jective satisfaction with verbal communication and $\operatorname{PCS}(\mathrm{r}=0.307, P<0.001)$ or $\operatorname{MCS}(\mathrm{r}=0.435, P<$ 0.001) in covariance structure analysis. Conclusions: Satisfaction with verbal communication is significantly related to HRQOL among Japanese community-dwelling elderly individuals.

\title{
Keywords
}

\author{
Subjective Satisfaction with Verbal Communication, HRQOL, Elderly, Community, Oral Health \\ Program
}

\section{Introduction}

Communication is very important in conveying our desires, ideas and emotions, and allowing us to achieve a better understanding of each other (Borden, Harris, \& Raphael, 1994). Communication consists of speaking, writing and reading, and gesturing; in addition, affirmative emotions, particularly when conveyed by smiling and laughing, promote good communication and transmit information smoothly. Interlocutors may derive pleasure and a sense of achievement and satisfaction from being successfully understood, particularly in the case of verbal communication.

Higashi et al. (2007) investigated the association between verbal communication and subjective well-being among Japanese elderly residents of rural communities, and reported that the frequent satisfaction derived from verbal communication with families or other rural residents improved their subjective well-being. In the case of aphasia patients, who face difficulties with verbal communication, conversational support from volunteers or professional interpreters trained in communication skills improved the patient's satisfaction with their communication, as well as providing them with more frequent opportunities for communication (Suzuki, 2012; Larsson \& Thoren-Jonsson, 2007). These reports indicated that richness in communication opportunities or smooth communication exchanges improved individual's satisfaction with communication, as well as their subjective wellbeing.

While evaluations of subjective well-being refer to the specific dimensions of psychological ill-health, the health-related quality of life (HRQOL) tool measures aspects related to bodily and mental health, as well as the role of individuals in social or daily life and their general well-being (Cummins, Lau, \& Stokes, 2004). Many pleasant daily activities, including recreation (Onishi et al., 2006), singing (Elefant et al., 2012; Tamplin, et al., 2013) and physical activity (Bertheussen et al., 2011), have been previously reported to enhance HRQOL. However, few studies have investigated the association between verbal communication and HRQOL in community residents.

Normal aging is associated with changes in speech that are physiologically, acoustically and perceptually detectable (Duffy, 2005). Moreover, tooth loss and decline of oral function also affect speech performance, which impacts verbal communication (Bassi et al., 2013; Knipfer et al., 2014). We suggest that the decline of speech performance affects an individual's satisfaction derived from verbal communication and lowers his HRQOL. Therefore, it is important to investigate the impact of oral function on satisfaction with verbal communication, and to investigate the association between the satisfaction with verbal communication and HRQOL.

Thus, the aim of this study is to examine subjective satisfaction with verbal communication, dentition and HRQOL using a questionnaire, and to investigate factors related to improving satisfaction with verbal communication among elderly residents of rural communities.

\section{Material and Methods}

\subsection{Subjects}

Satisfaction with verbal communication, dentition, and HRQOL were evaluated using a self-administered questionnaire. Four hundred and fifty-four independent elderly individuals over 65 years of age living in northern Miyazaki Prefecture, Japan, agreed the participation the study. Of those initial subjects, 454 subjects (77.0\%), with a mean age of $76.1 \pm 6.8$ years, responded and completed the questionnaire. 
This study was approved by the Ethical Review Board, National Institute of Public Health (approval ID: NIPH-IBRA\#10050). All subjects gave their informed consent to participate the study.

\subsection{Instruments}

\subsubsection{Investigation of HRQOL}

The SF-8 Health Survey Japanese version (SF-8: Fukuhara \& Suzukamo, 2004) was used to evaluate the subjects' HRQOL. SF-8 comprises eight items: Physical Functioning (PF), Role (Physical: RP), Bodily Pain (BP), General Health Perception (GH), Vitality (VT), Social Functioning (SF), Role (Emotional: RE) and Mental Health (MH). The SF-8 score is equivalent to SF-36 (Miyashita et al., 2011). SF-8 had a correlation at as high as $0.58-0.87$ with the eight lower parameters of SF-36, and test-retest reliability of SF-8 was revealed as high as 0.67- 0.91 ineachitem (Fukuhara \& Suzukamo, 2004; Inoue, 2011). We also calculated physical component summary (PCS) and mental component summary (MCS) scores (SF-36.org, 2014). Test-retest reliability was 0.73 in PCS and 0.74 in MCS (Fukuhara \& Suzukamo, 2004).

\subsubsection{Subjective Satisfaction with Verbal Communication}

Subjective satisfaction with verbal communication was subjectively rated by each participant. We questioned "are you satisfying in your daily talking with friends or others", and we used five categories: "very satisfied", "satisfied", "neither satisfied nor unsatisfied", "unsatisfied" and "very unsatisfied".

\subsubsection{Dental Status}

Dental status was classified into five categories as follows: all natural teeth, natural teeth with partial denture, denture of upper or lower jaw, full denture, and no teeth or denture.

\subsection{Analysis}

Unpaired t-test or chi-square test was conducted to compare age, SF-8 summary scores, satisfaction with verbal communication status and dentition between the gender groups. Pearson's correlation coefficient analysis was conducted to examine the association between satisfaction with verbal communication and HRQOL subscores. One-way ANOVA with Bonferroni's post-hoc test was conducted to compare age or HRQOL between groups categorized according to subjective satisfaction with verbal communication or dentition. We also used the chisquare test to analyze the association of satisfaction with verbal communication between the groups according to dentition status. Furthermore, multiple regression analysis by forced entry method was also conducted to identify the determinants affecting HRQOL. Covariance structure analysis was performed to investigate the mutual interrelationship between the factors, with significant associations analyzed by ANOVA, unpaired t-test, or chisquare test. We calculated the standardized parameter estimates using path model analysis and used a significance level of $P<0.05$ for the regression coefficients. We also calculated the goodness of fit index (GFI), adjusted goodness of fit index (AGFI), comparative fit index (CFI), and root mean square error of approximation (RMSEA) to examine the goodness of fit in the model. A value of $>0.95$ for GFI, AGFI, and CFI, and of $<0.06$ for RMSEA are considered to indicate a good fit of the data to the model (Furuta et al., 2013).

All analyses were performed using IBM SPSS statistical software Japanese version 20.0 and AMOS Japanese version 20.0.

\section{Results}

Univariate data of the subjects are shown in Table 1. A comparison of our data to Japanese norm-based scoring of 70 - 75 years old subjects (Fukuhara \& Suzukamo, 2004) revealed that all subscale and summary scores of our subjects were within the 1-standard-deviation range. Three hundred and fifty-two subjects (77.5\%) answered that they were "very satisfied" or "satisfied" with verbal communication. When the gender groups were compared, PCS scores in the male group were significantly higher than those in the female group $(P<0.05)$. The ratio of subjects with all natural tooth dentition in the male group $(20.6 \%)$ was significantly higher than that in the female group $(8.7 \%, P<0.01)$. Subject in no teeth or denture group was only one $(0.2 \%)$ subject, so we used the 4 dental status group (all natural tooth, natural tooth with partial denture, denture on upper or lower jaw, and full denture or no tooth) to investigate the association between the dental status and other factors in the later analysis. 
Table 1. Age, HRQOL, satisfaction for communication, and dental status in 454 elderly subjects, and comparison those data between the gender group.

\begin{tabular}{|c|c|c|c|c|}
\hline & $\begin{array}{c}\text { All } \\
\mathrm{n}=454\end{array}$ & $\begin{array}{c}\text { Male } \\
\mathrm{n}=189\end{array}$ & $\begin{array}{l}\text { Female } \\
n=265\end{array}$ & $P$-value \\
\hline Age, yr. & $75.9(6.8)$ & $75.8(6.1)$ & $76.3(7.1)$ & ns \\
\hline \multicolumn{5}{|l|}{ SF-8, summery score $(\mathrm{SD})$} \\
\hline PCS & $46.52(5.96)$ & $47.27(5.54)$ & $45.98(6.19)$ & * \\
\hline MCS & $50.29(6.36)$ & $50.60(6.66)$ & $50.08(6.14)$ & ns \\
\hline \multicolumn{5}{|c|}{ Subjective satisfaction with verbal communication, number $(\%)$} \\
\hline Very satisfied & $115(25.3)$ & $42(22.2)$ & $73(27.3)$ & \\
\hline Satisfied & $237(52.2)$ & $105(55.6)$ & $132(55.7)$ & \\
\hline Neither satisfied nor unsatisfied & $85(18.7)$ & $35(18.5)$ & $50(18.9)$ & ns \\
\hline Unsatisfied & $15(3.3)$ & $7(3.7)$ & $8(3.0)$ & \\
\hline Very unsatisfied & $2(0.4)$ & $0(0.0)$ & $2(0.8)$ & \\
\hline \multicolumn{5}{|l|}{ Dental status, number (\%) } \\
\hline All natural tooth & $62(13.7)$ & $39(20.6)$ & $23(8.7)$ & \multirow{5}{*}{$* *$} \\
\hline Natural tooth with partial denture & $226(49.8)$ & $93(49.2)$ & $133(50.2)$ & \\
\hline Denture on upper or lower jaw & $54(11.9)$ & $24(12.7)$ & $30(11.3)$ & \\
\hline Full denture & $111(24.4)$ & $33(17.5)$ & $79(29.4)$ & \\
\hline No teeth or denture & $1(0.2)$ & $0(0.0)$ & $1(0.4)$ & \\
\hline
\end{tabular}

ns: not significant; ${ }^{*} P<0.05 ;{ }^{* *} P<0.01$ compared between the gender.

Satisfaction with verbal communication had significantly positive correlations with SF-8 subscores $(\mathrm{r}=0.397$ in PCS, 0.482 in MCS; $P<0.001)$. All subscores of SF-8 among subjects who answered that they were "very satisfied" or "satisfied" with verbal communication were significantly higher than those of subjects who answered that they were "neither satisfied nor unsatisfied", "unsatisfied" or "very unsatisfied" $(P<0.001$ : Figure 1). The mean age of subjects who were very satisfied with verbal communication was significantly lower than that of subjects in the "neither satisfied nor unsatisfied" group $(P<0.05)$.

Comparisons of SF-8 scores between age and dentition groups are shown in Table 2. PCS or MCS scores in the full denture or no teeth groups were significantly lower than those in the other three groups $(P<0.05)$. We compared the satisfaction with verbal communication between the groups with natural teeth present. The proportion who were "very satisfied" and "satisfied" among the subjects with natural teeth (all natural teeth, natural teeth with partial denture, or denture on upper or lower jaw) was higher than in those of the subjects with no natural teeth (full denture or no teeth or denture; $80.7 \%$ in the subjects with natural teeth, and $67.9 \%$ in the subjects with no natural teeth, $P<0.001)$.

The results of multiple regression analysis are shown in Table 3. Age, gender (male $=1$ and female $=0$ ), subjective satisfaction with verbal communication ("very satisfied" or "satisfied" $=1$, others $=0$ ), and presence of natural teeth (full denture or no teeth $=0$ and others $=1$ ) were entered as independent variables of PCS or MCS scores. Younger age, male gender, and good subjective satisfaction with verbal communication were independent predictors of higher PCS (adjusted $\mathrm{R}^{2}=0.248, P<0.001$ ). Younger age and good subjective satisfaction with verbal communication were also independent predictors of higher MCS (adjusted $\mathrm{R}^{2}=0.235, P<$ $0.001)$.

The model of covariance structure analysis is shown in Figure 2. The model fit was GFI $=0.997$, AGFI $=$ $0.977, \mathrm{CFI}=0.995$ and RMSEA $=0.034$. There was a significant positive correlation between subjective satisfaction with verbal communication and PCS $(\mathrm{r}=0.307, P<0.001)$ or $\mathrm{MCS}(\mathrm{r}=0.435, P<0.001)$. Age had significant negative correlations with PCS $(\mathrm{r}=-0.315, P<0.001)$ and $\operatorname{MCS}(\mathrm{r}=-0.132, P<0.01)$ and male gender had a significant positive correlation with PCS $(\mathrm{r}=0.091, P<0.05)$. The presence of natural teeth was significantly negatively correlated with age $(\mathrm{r}=-0.355, P<0.001)$ and was positively correlated with male gender $(\mathrm{r}=0.141, P<0.01)$. However, no significant correlation was shown between the presence of natural teeth and subjective satisfaction with verbal communication or HRQOL. 


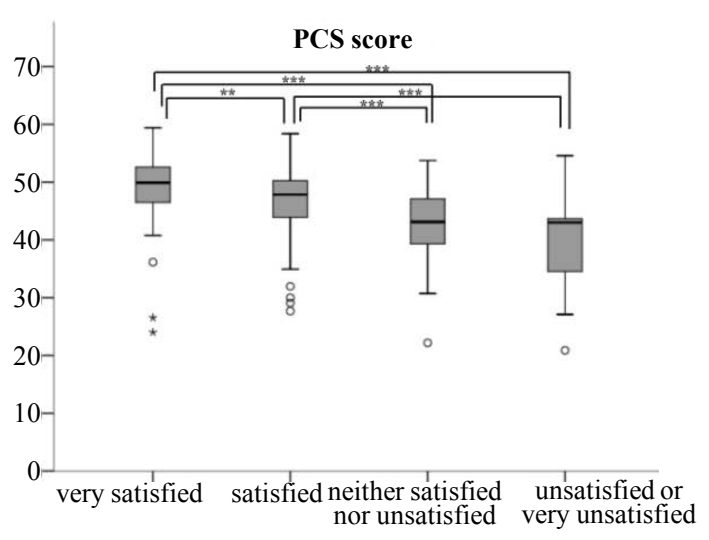

Satisfaction with verbal communication

${ }^{* *} P<0.01 ;{ }^{* * *} P<0.001$.

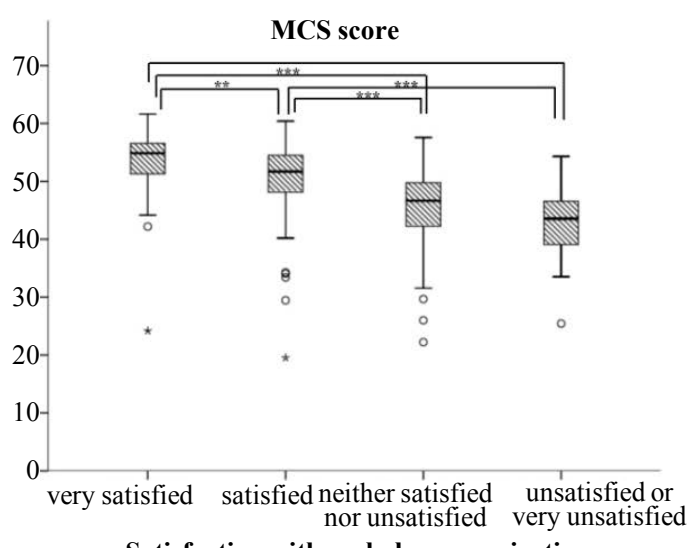

Satisfaction with verbal communication

Figure 1. Comparison of PCS (left) and MCS (right) scores between the satisfactions with verbal communication groups.

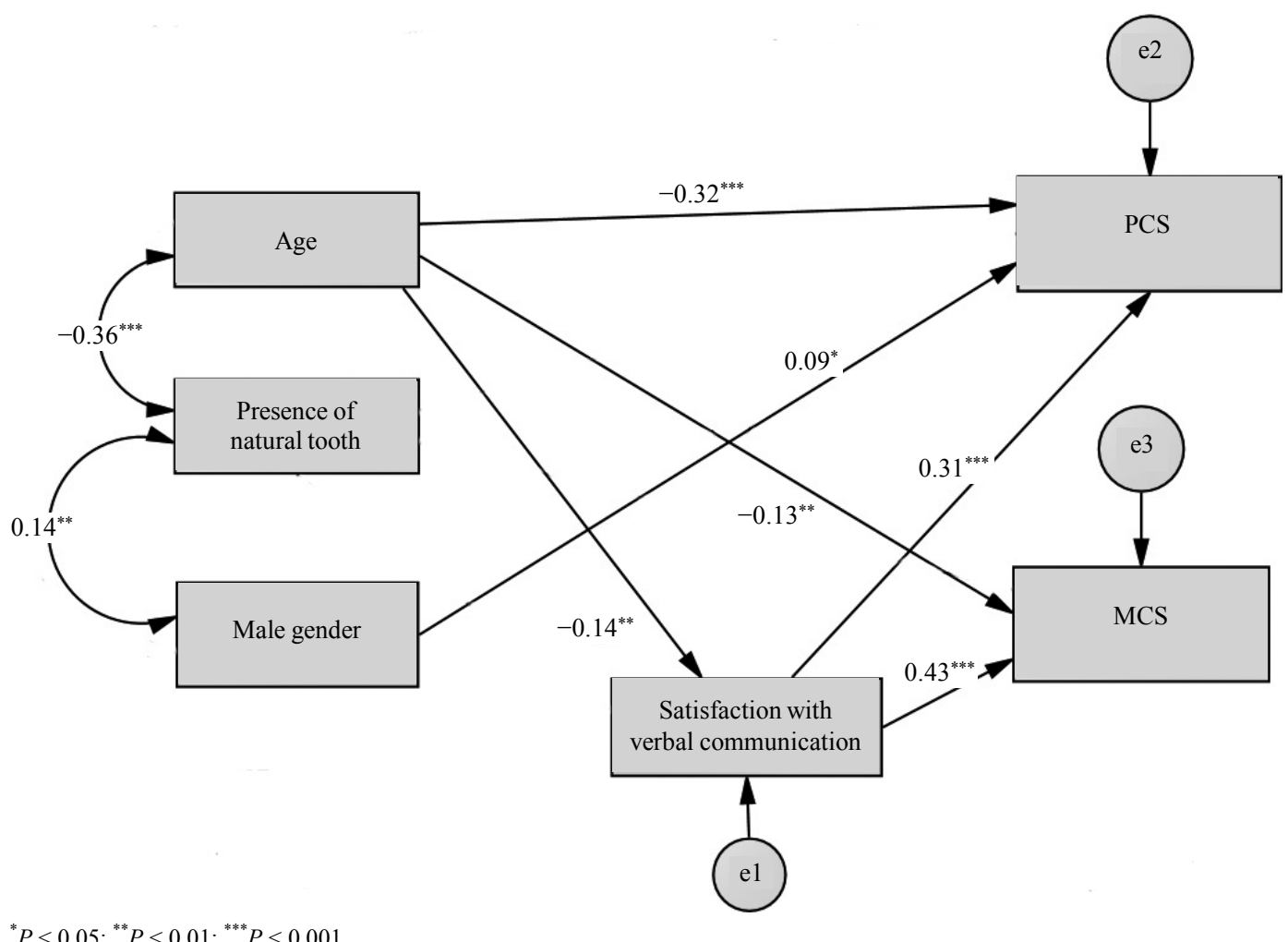

Figure 2. Model of the HRQOL-related factors by covariate structure analysis: GFI = 0.997; AGFI = 0.977; $\mathrm{CFI}=0.995 ;$ RMSEA $=0.034$.

Table 2. Comparison of age and HRQOL between the dental status groups.

\begin{tabular}{ccccc}
\hline & $\begin{array}{c}\text { All natural tooth } \\
\mathrm{n}=62\end{array}$ & $\begin{array}{c}\text { Natural tooth with partial denture } \\
\mathrm{n}=226\end{array}$ & $\begin{array}{c}\text { Denture on upper or lower jaw } \\
\mathrm{n}=54\end{array}$ & $\begin{array}{c}\text { Full denture or no tooth } \\
\mathrm{n}=112\end{array}$ \\
\hline Age & $74.8(6.1)^{* * *}$ & $74.2(6.1)^{* * *}$ & $75.7(6.5)^{* * *}$ & $80.2(6.8)$ \\
PCS & $47.55(6.26)^{* *}$ & $46.93(5.96)^{* *}$ & $47.86(5.43)^{* *}$ & $44.45(5.57)$ \\
MCS & $51.59(5.57)^{*}$ & $50.70(6.02)^{*}$ & $50.45(6.27)$ & $48.68(7.19)$
\end{tabular}

Score (SD). ${ }^{*} P<0.05{ }^{* *} P<0.01{ }^{* * *} P<0.001$ vs. full denture or no teeth group. 
Table 3. Determinants to the good HRQOL analyzed by multiple regression analysis"

\begin{tabular}{ccc}
\hline & PCS & MCS \\
\hline Age, +1 & $-0.276^{* * *}$ & $-0.137^{* *}$ \\
Sex, male & $1.099^{*}$ & 0.378 \\
Good satisfaction in conversation & $4.380^{* * *}$ & $6.622^{* * *}$ \\
Presence of natural tooth & 0.460 & 0.531 \\
Multiple R & 0.498 & 0.484 \\
$\mathrm{R}^{2}$ (adjusted) & 0.242 & 0.230 \\
Significance F & $P<0.001$ & $P<0.001$ \\
\hline
\end{tabular}

${ }^{*} P<0.05 ;{ }^{* *} P<0.01 ;{ }^{* * *} P<0.001$. "Analyzed by related factors below: age, sex (male $=1$ ), satisfaction in conversation ("very satisfied" or "satisfied" $=1$, others $=0$ ), and presence of natural tooth ("natural tooth" $=1$, others $=0$ ).

\section{Discussion}

Our findings indicate that good subjective satisfaction with verbal communication is associated with an improved HRQOL among community-dwelling elderly individuals. In Japan, oral health programs for the elderly are one of the interventions that aim to prevent the need for nursing care. The program may play an important role in patients' oral functional status by reducing the risk of oral functional problems, maintaining or improving oral function, and enabling patients to enjoy a healthy daily life. The report of a study that investigated the association between social communication and QOL in Japanese elderly (Tanno, 2010) concluded that self-disclosure in social communication situations promoted daily comfort. Our findings also suggest that a program designed to establish situations involving friendly exchanges and an increase in friendship through communication with all elderly participants, has the potential to maintain or increase each participant's HRQOL and health status.

Higher PCS scores were significantly associated with gender in the present study. In our previous study (Hara, Miura, \& Yamasaki, 2013), we investigated oral diadochokinesis (OD) in community-dwelling subjects and compared age groups and gender groups. We found that OD tends to decrease from age 65 , with the decline in OD clearly beginning earlier in women than in men. OD is used to evaluate the speed and regularity of reciprocal movement of the jaw, lips, and anterior or posterior tongue and hence, this measurement also provides an assessment of the articulatory movement (Duffy, 2005). Our present study suggests that the decline in articulatory ability in women caused reduced satisfaction with verbal communication and was related to the lower physical HRQOL. Sakayori et al. (2013) reported that a 3-month intervention, which included oral physical exercises, singing, and pronunciation exercises, effected an improvement in the OD score for high-risk elderly patients. Our results indicate that exercises, including pronunciation or singing, may improve the articulatory ability, maintain a better level of satisfaction with verbal communication, and result in a better HRQOL.

In our present study, we found a significant association between the subjective satisfaction of communication and dental state, or HRQOL in bivariate analysis. Multiple regression analysis was conducted to investigate the association of the above factors adjusted for age and gender. Covariate structural analysis and path model analysis were also conducted to clarify the mutual relationship between these factors. Satisfaction with verbal communication was a significant determinant of higher HRQOL; however, no significant association was shown between dental state and communication, or HRQOL in both analyses. We evaluated the dentition only by the questionnaire; we were not able to investigate the details of the dental status, for example, presence of missing teeth, bridges, and dental implant. We need to survey the association between above factors and satisfaction with verbal communication, or HRQOL. Furthermore, in previous studies, intraoral state, including factors such as the suitability of a denture (Knipfer et al., 2014; Broka et al., 2013; Adaki, Meshram, \& Adaki, 2013), hyposalivation (Samnieng et al., 2012), gingival abscesses (Holtzclaw \& Toscano, 2008), and mastication and swallowing function (Sapir, Ramig, \& Fox, 2008; Vogel et al., 2014), may be associated with communicational status and satisfaction. Therefore, further studies, which investigate the above factors, are necessary to examine whether there is any association between subjective communicational satisfaction and HRQOL.

Our present study was also a cross-sectional study. Hence, further prospective studies are needed to investigate any correlation between subjective satisfaction with verbal communication and HRQOL among participants of a long-term care-prevention program. It will also be necessary to carry out additional studies of a subjects' 
health-care behavior to investigate whether other health activities or programs improve satisfaction with verbal communication as well as HRQOL.

\section{Conclusion}

In conclusion, satisfaction with verbal communication improves HRQOL among Japanese community-dwelling elderly individuals. Therefore, programs for the elderly, which include exchanges involving communication, may play an important role in improving their HRQOL.

\section{Acknowledgements}

This work was supported by Grants-in-Aid for Scientific Research (C) No. 23593115 (Hara S., Miura H., and Yamasaki K.) and No. 22500688 (Miura H., Hara S., and Yamasaki K.) from the Japan Society for the Promotion of Science and Grants-in-Aid for Scientific Research No. 22110101 (Osaka K.) from the Ministry of Health, Labor and Welfare. The authors thank all those who responded to our questionnaire. We also thank the public health nurses in the northern area of Miyazaki prefecture for distributing and collecting the questionnaire. Part of this study was previously presented at the 20th IAGG World Congress of Gerontology and Geriatrics (June 26, Seoul, Korea).

\section{Disclosure Statement}

No potential conflicts of interest were disclosed.

\section{References}

Adaki, R., Meshram, S., \& Adaki, S. (2013). Acoustic Analysis and Speech Intelligibility in Patients Wearing Conventional Dentures and Rugae Incorporated Dentures. Journal of Indian Prosthodontic Society, 13, 413-420. http://dx.doi.org/10.1007/s13191-013-0262-x

Bassi, F., Carr, A.B., Chang, T.L., Estafanous, E.W., Garrett, N.R., Happonen, R.P. et al. (2013). Functional Outcomes for Clinical Evaluation of Implant Restorations. The International Journal of Prosthodontics, 26, 411-418. http://dx.doi.org/10.11607/ijp.3404

Bertheussen, G. F., Romundstad, P. R., Landmark, T., Kaasa, S., Dale, O., \& Helbostad, J. L. (2011). Associations between Physical Activity and Physical and Mental Health-A HUNT 3 Study. Medicine \& Science in Sports \& Exercise, 43, 1220-1228. http://dx.doi.org/10.1249/MSS.0b013e318206c66e

Borden, G. J., Harris, K. S., \& Raphael, L. J. (1994). Speech, Language, and Thought. In G. J. Borden, K. S. Harris, \& L. J. (Eds.), Raphael Speech Science Primer: Physiology, Acoustics, and Perception of Speech (3rd ed., pp. 1-13). Baltimore: Williams and Wilkins.

Broka, K., Vidzis, A., Grigorjevs, J., Sokolovs, J., \& Zigurs G. (2013). The Influence of the Design of Removable Dentures on Patient's Voice Quality. Stomatologija, 15, 20-25.

Cummins, R. A., Lau, A., \& Stokes, M. (2004). HRQOL and Subjective Well-Being: Noncomplementary Forms of Outcome Measurement. Expert Review of Pharmacoeconomics and Outcomes Research, 4, 413-420. http://dx.doi.org/10.1586/14737167.4.4.413

Duffy, J. R. (2005). Motor Speech Disorders. Substrates, Differential Diagnosis, and Management (2nd ed., pp. 3-16, 84-85). Philadelphia: Elsevier Mosby.

Elefant, C., Baker, F. A., Lotan, M., Lagesen, S. K., \& Skeie, G. O. (2012).The Effect of Group Music Therapy on Mood, Speech, and Singing in Individuals with Parkinson's Disease-A Feasibility Study. Journal of Music Therapy, 49, 278302. http://dx.doi.org/10.1093/jmt/49.3.278

Fukuhara, S., \& Suzukamo, Y. (2004). Manual of the SF-8 Japanese Version. Kyoto: Institute for Health Outcomes and Process Evaluation Research.

Furuta, M., Komiya-Nonaka, M., Akifusa, S., Shimazaki, Y., Adachi, M., Kinoshita, T. et al. (2013). Interrelationship of Oral Health Status, Swallowing Function, Nutritional Status, and Cognitive Ability with Activities of Daily Living in Japanese Elderly People Receiving Home Care Services Due to Physical Disabilities. Community Dentistry and Oral Epidemiology, 41, 173-181. http://dx.doi.org/10.1111/cdoe.12000

Hara, S., Miura, H., \& Yamasaki, K. (2013). Oral Diadochokinesis among Japanese Aged over 55 Years: Analysis of Standard Values. Nippon Ronen Igakkai Zasshi, 50, 258-263. http://dx.doi.org/10.3143/geriatrics.50.258 
Higashi, N., Ohsawa, M., Watanabe, S., \& Kawarada, M. (2007). Association between Verbal Communication and Subjective Well-Being among Japanese Community-Residing Elderly. Hokkaido Journal of Public Health, 21, 90-97.

Holtzclaw, D., \& Toscano, N. (2008). Speech Pattern Improvement Following Gingivectomy of Excess Palatal Tissue. Journal of Periodontology, 79, 2006-2009. http://dx.doi.org/10.1902/jop.2008.080090

Inoue, T. (2011). Efficacyof SF-8 Inchronicrespiratory Diseasecase. Respiratory Care and Pulmonary Aspiration Care, 4, $11-16$.

Knipfer, C., Riemann, M., Bocklet, T., Noeth, E., Schuster, M., Sokol, B. et al. (2014). Speech Intelligibility Enhancement after Maxillary Denture Treatment and Its Impact on Quality of Life. International Journal of Prosthodontics, 27, 61-69. http://dx.doi.org/10.11607/ijp.3597

Larsson, I., \& Thoren-Jonsson, A. L. (2007). The Swedish Speech Interpretation Service: An Exploratory Study of a New Communication Support Provided to People with Aphasia. Augmentative and Alternative Communication, 23, 312-322. http://dx.doi.org/10.1080/07434610601180026

Miyashita, M., Narita, Y., Sakamoto, A., Kawada, N., Akiyama, M., Kayama, M. et al. (2011). Health-Related Quality of Life among Community-Dwelling Patients with Intractable Neurological Diseases and Their Caregivers in Japan. Psychiatry and Clinical Neurosciences, 65, 30-38. http://dx.doi.org/10.1111/j.1440-1819.2010.02155.x

Onishi, J., Masuda, Y., Suzuki, Y., Gotoh, T., Kawamura, T., \& Iguchi, A. (2006). The Pleasurable Recreational Activities among Community-Dwelling Older Adults. Archives of Gerontology and Geriatrics, 43, 147-155. http://dx.doi.org/10.1016/j.archger.2005.10.003

Sakayori, T., Maki, Y., Hirata, S., Okada, M., \& Ishii, T. (2013). Evaluation of a Japanese "Prevention of Long-Term Care" Project for the Improvement in Oral Function in the High-Risk Elderly. Geriatrics \& Gerontology International, 13, 451457. http://dx.doi.org/10.1111/j.1447-0594.2012.00930.x

Samnieng, P., Ueno, M., Shinada, K., Zaitsu, T., Wright, F. A., \& Kawaguchi, Y. (2012). Association of Hyposalivation with Oral Function, Nutrition and Oral Health in Community-Dwelling Elderly Thai. Community Dental Health, 29, 117-123.

Sapir, S., Ramig, L., \& Fox, C. (2008). Speech and Swallowing Disorders in Parkinson Disease. Current Opinion in Otolaryngology \& Head and Neck Surgery, 16, 205-210. http://dx.doi.org/10.1097/MOO.0b013e3282febd3a

SF-36.org (2014). The SF-8 ${ }^{\text {TM }}$ Health Survey. http://www.sf-36.org/tools/sf8.shtml

Suzuki, T. (2012). Actual Situation and Views with Support Services for People with Aphasia by Conversation Partners. Journal of Health and Medical Science, 2012, 27-38.

Tamplin, J., Baker, F. A., Grocke, D., Brazzale, D. J., Pretto, J. J., Ruehland, W. R. et al. (2013). Effect of Singing on Respiratory Function, Voice, and Mood after Quadriplegia: A Randomized Controlled Trial. Archives of Physical Medicine and Rehabilitation, 94, 426-434. http://dx.doi.org/10.1016/j.apmr.2012.10.006

Tanno, H. (2010). The Function of Friendship in QOL of Older Group. Japanese Journal of Interpersonal and Social Psychology, 10, 125-129.

Vogel, A. P., Brown, S. E., Folker, J. E., Corben, L. A., \& Delatycki, M. B. (2014). Dysphagia and Swallowing-Related Quality of Life in Friedreich Ataxia. Journal of Neurology, 261, 392-399. http://dx.doi.org/10.1007/s00415-013-7208-4 
Scientific Research Publishing (SCIRP) is one of the largest Open Access journal publishers. It is currently publishing more than 200 open access, online, peer-reviewed journals covering a wide range of academic disciplines. SCIRP serves the worldwide academic communities and contributes to the progress and application of science with its publication.

Other selected journals from SCIRP are listed as below. Submit your manuscript to us via either submit@scirp.org or Online Submission Portal.
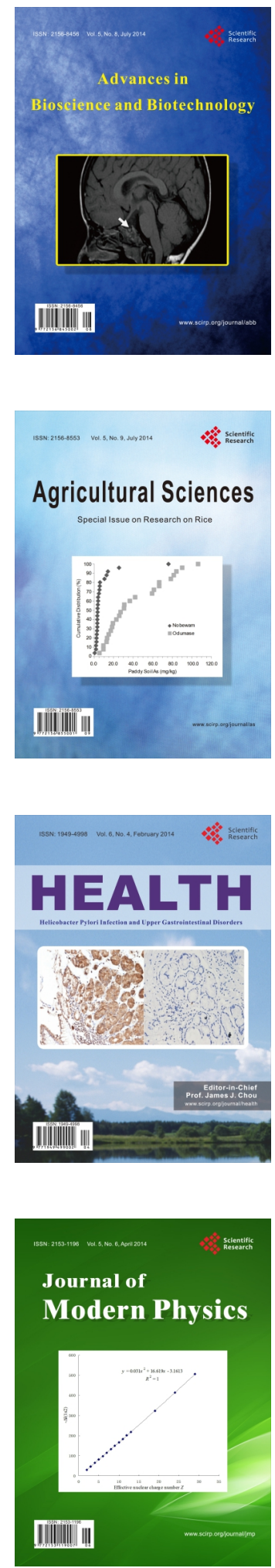
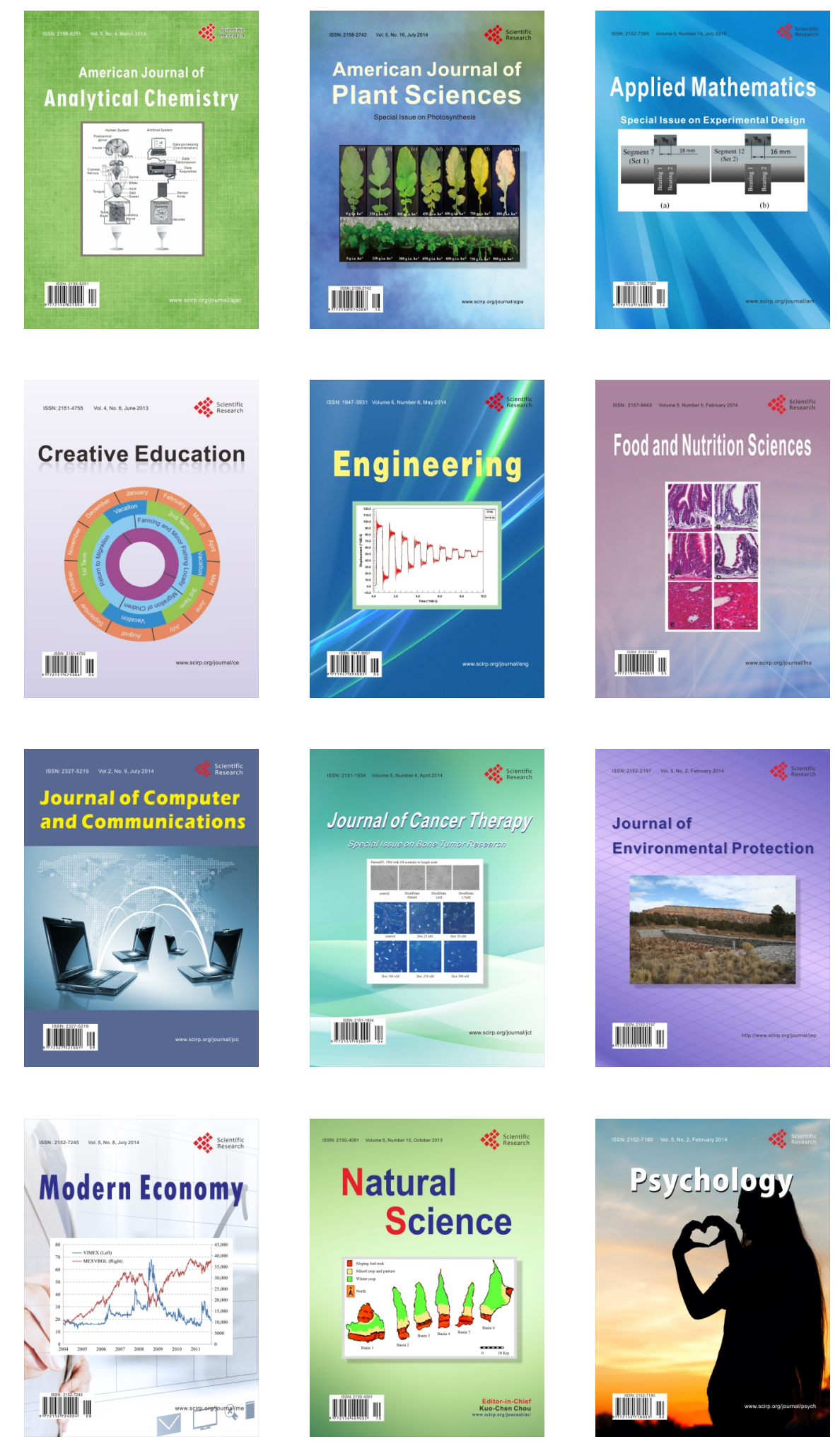